\title{
Digital Image Analysis of Mean AgNOR Area Objectively Discriminates between Reactive Plasmacytosis and Multiple Myeloma in Cytologic Smears from Bone Marrow Aspirates
}

\author{
S. Gunia P.A. Mai S. Koch \\ Institute of Pathology, HELIOS Clinics Bad Saarow, Charité-University Medicine Teaching Hospital, Bad Saarow, \\ Germany
}

\section{Key Words}

AgNOR area $\cdot$ Bone marrow aspirates $\cdot$ Digital image analysis $\cdot$ Multiple myeloma $\cdot$ Reactive plasmacytosis

\begin{abstract}
Objective: To differentiate between reactive plasmacytosis (RP) and multiple myeloma (MM) in bone marrow aspirates by assessment of silver-stainable nucleolar organizer regions (AgNORs). Methods: Archival cytologic smears $(n=69)$ from bone marrow aspirates were retrospectively investigated. Twenty cases had RP and 49 cases MM (24 low-grade, 22 intermediate-grade and 3 high-grade MM). Diagnoses were confirmed by evaluation of the corresponding bone marrow trephine biopsies. Cytologic smears were subjected to AgNOR staining using a standardized silver-staining protocol and assessed by two independent clinical histopathologists using digital image analysis. AgNOR count and area were analyzed in 100 plasma cell nuclei per sample. Results: The mean AgNOR area was found to be significantly $(p<$ 0.001 ) higher in low-grade MM (mean: $23.4 \mu \mathrm{m}^{2}$; range: $19.2-$ $26.7 \mu \mathrm{m}^{2}$ ) than in RP cases (mean: $6.2 \mu \mathrm{m}^{2}$; range: 3.8-8.4 $\mu \mathrm{m}^{2}$ ). In contrast, mean AgNOR count failed to disclose significant differences between low-grade MM (mean: 5.36; range: 1-7) and RP (mean: 3.68; range: 1-6). Conclusion: Dig-
\end{abstract}

ital image analysis of the mean AgNOR area might be used as a diagnostically useful adjunct to aid objectively in the challenging differentiation between RP and MM in bone marrow aspirates.

Copyright $\odot 2008$ S. Karger AG, Basel

\section{Introduction}

Approximately $15 \%$ of all hematological malignancies affect patients with a median age of 68 years in males and 70 years in females in the United States [1]. Amongst these, multiple myeloma (MM) is a bone marrow-based disease resulting from the proliferation of a clone of neoplastic cells which are closely related to plasma cells (PC) occurring in the middle-aged and elderly population.

For bone marrow trephine biopsies, conventional major and minor criteria required for MM diagnosis have been well established [2]. Immunohistochemistry and in situ hybridization $[3,4]$ can be applied to equivocal cases. However, using cytologic smears from bone marrow aspirates, the differential diagnosis between low-grade MM and reactive plasmacy tosis (RP) might be challenging [5], underlining the need for objective morphological criteria facilitating the conventional discrimination.

\section{KARGER \\ Fax +4161306 1234 \\ E-Mail karger@karger.ch}

www.karger.com (c) 2008 S. Karger AG, Basel

1015-2008/08/0755-0306\$24.50/0

Accessible online at:

www.karger.com/pat
Dr. Sven Gunia

Institut für Pathologie, HELIOS Klinikum Bad Saarow

Pieskower Strasse 33

DE-15526 Bad Saarow (Germany)

Tel. +4933631 72312, Fax +4933631 73010, E-Mail sven.gunia@helios-kliniken.de 
Nucleolar organizer regions (NORs) are nucleolar components containing loops of DNA actively transcribing into ribosomal RNA (rRNA) genes. These are selectively stained by silver methods [6], which stain NORs as black dots of different size, shape and number. In the past, AgNORs have attracted considerable attention in tumor biology because of their relation to cell proliferation [7].

In MM, mean AgNOR counts have been found to be reliable predictors of survival [8] and suggested to reflect the myeloma cell mass and the kinetics of myeloma cells [9], but a thorough comparative analysis of the mean AgNOR count and area has not yet been performed with respect to the challenging differential diagnosis of PC proliferations encountered in bone marrow aspirates. This so far neglected evaluation was defined to be the goal of the present study.

\section{Materials and Methods}

\section{Specimen Selection}

Retrospective computerized database analysis was performed in order to identify all patients with newly diagnosed MM and RP between 1995 and 1998, from whom bone marrow trephine biopsies and aspirates were available at the Institute of Pathology, HELIOS Clinics Bad Saarow (the former HUMAINE Clinics), Germany. A total of 69 archival cytologic smears previously stained with the Papanicolaou technique and their corresponding 69 trephine biopsies were retrieved from the files of the Institute of Pathology. The reference collective comprised 20 cases of RP (mean age: 54.2 years; range: $31-82$ years), and 49 cases had MM (mean age: 59.3 years; range: $28-86$ years). The latter group included 24 low-grade (G1), 22 intermediate-grade (G2) and 3 high-grade (G3) MM based on the grading criteria devised by Bartl et al. [10]. Patients assigned to the reference collective $(n=20)$ suffered from hemopoietic malignant diseases other than MM and were found to have accompanying reactive increase in PC. These patients were consistently kept under regular clinical follow-up at the Department of Hematology and Oncology, HELIOS Clinics Bad Saarow, in order to exclude any progress to PC dyscrasia (mean follow-up 4.2 years; range: $3-7$ years).

MM were preliminarily categorized in terms of patterns of medullary involvement (interstitial, nodular and/or diffuse) and percentage of PC in aspirates and bone marrow biopsies. The 'nodular pattern' of infiltration was defined as a random infiltrate with a well-defined round border between hematopoietic and fat cells.

\section{Immunohistochemistry and in situ Hybridization}

Bone marrow trephine biopsy specimens were wax embedded and cut into $4-\mu \mathrm{m}$-thick serial sections and prepared for this study following decalcification according to the approach described by Schaefer [11]. For immunohistochemistry, the sections were deparaffinized with graded series of alcohol and xylene. Thermal antigen demasking $\left(100^{\circ} \mathrm{C}\right)$ was performed in $0.01 \mathrm{M}$ citrate buffer for $30 \mathrm{~min}$, automatically performed by the Bond $^{\mathrm{TM}}$ system (Vision BioSystems, Mount Waverley, Vic., Australia). Monoclonal anti-CD138 (clone: 5F7, 1:80 dilution; Novocastra Laboratories, Newcastle-upon-Tyne, UK) was applied as the primary antibody for decoration of $\mathrm{PC}$, and was incubated at room temperature for $1 \mathrm{~h}$. Subsequently, sections were washed with PBS and incubated with rabbit anti-mouse IgG (1:50) followed by mouse peroxidase-antiperoxidase conjugate (1:200). The enzymatic reaction was developed in a freshly prepared solution of diaminobenzidine $(0.5 \mathrm{mg} / \mathrm{ml}$; Sigma, Deisenhofen, Germany) and $0.01 \%$ hydrogen peroxide in water. Negative controls were prepared by omitting the first-layer antibody. Trephine biopsies were subsequently subjected to the detection of immunoglobulin light-chain mRNA by means of Bond in situ hybridization employing lambda (catalog No. PB0669) and kappa (catalog No. PB0645) probes according to the manufacturer's instructions.

\section{AgNOR Staining}

Smears were simultaneously processed under the same conditions according to the standardized approach described by Fiorella et al. [12]. Briefly, following removal of coverslips from the glass slides, destaining was performed with $5 \%$ aqueous trichloroacetic acid for $5 \mathrm{~min}$. After rinsing with distilled water and drying, the slides were stained with two drops of a working solution consisting of two parts $50 \%$ aqueous silver nitrate and one part $2 \%$ gelatin in $1 \%$ formic acid. They were then again covered with a coverslip and kept in a dark room for 20 min. Thereafter, coverslips were again removed and the slides were washed in distilled water, dehydrated and mounted after counterstaining with Giemsa (fig. 1).

\section{AgNOR Count and Morphometry}

Morphometric analysis was performed on silver-stained cytologic smears of bone marrow aspirates using a semiautomatic computer-assisted digital interactive image analyzer (IBAS2000; Kontron, Oberkochen, Germany) which consisted of a magnetic tablet connected with a microcomputer and lightemitting diode. Smears were viewed by means of a microscope equipped with a camera lucida, using an oil immersion objective with a final magnification of $\times 1,800$ in order to make AgNOR separation straightforward. Following accurate outlining of AgNOR boundaries using the light-emitting diode projection onto the microscopic field of study, AgNOR areas were calculated automatically. Additionally, the total number of AgNORs per PC nucleus were counted considering a total of 100 different PC nuclei in each specimen. All smears were independently assessed by two clinical histopathologists (P.A.M. and S.K.) and reassessed later in order to analyze intra- and interobserver variability.

\section{Statistical Analysis}

The nonparametric Mann-Whitney $U$ test was used to statistically compare AgNOR count and area among the different groups (RP, low-grade and intermediate-grade MM) except for high-grade $\mathrm{MM}$ due to the limited number of cases available $(n=3)$. Receiver-operating characteristic curve (ROC) analysis was performed in order to determine the optimal cutoff point in terms of differentiation between RP and MM. Intra- and interob- 

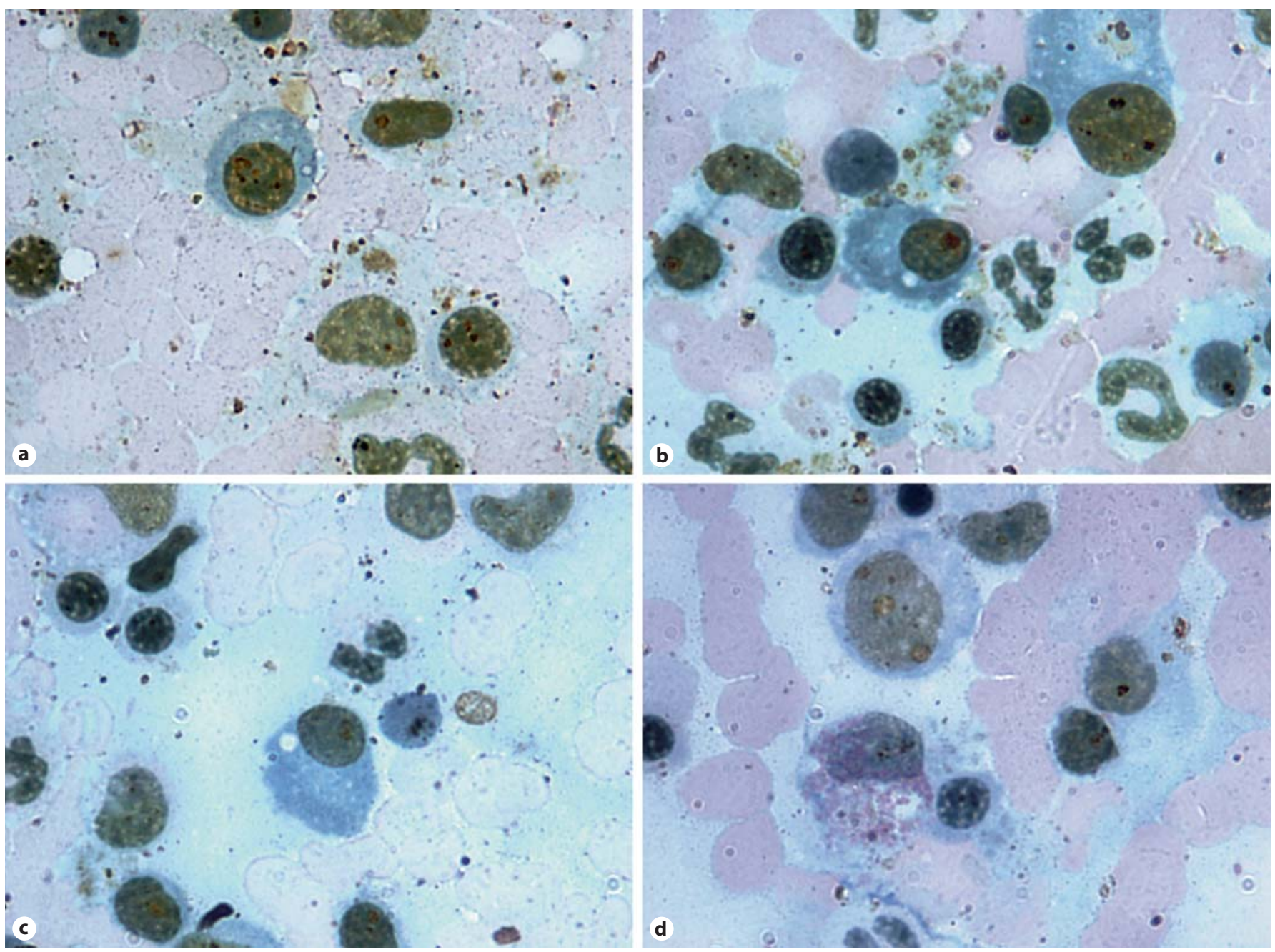

Fig. 1. Silver-impregnated Giemsa-stained cytologic smears from bone marrow aspirates. Note the steady increase in AgNOR areas when comparing RP (a), low-grade (b), intermediate-grade (c) and high-grade (d) MM. $\times 100$ objective.

server reliability was established by means of Cohen weighted $\kappa$ statistics. $\mathrm{p}<0.05$ was considered significant. All calculations were performed using the statistical software package SPSS 13.0.

\section{Results}

\section{Histopathology of Medullary Involvement of MM} and $R P$

All MM cases showed approximately 25-30\% of neoplastic PC in bone marrow trephine biopsies and aspirates, consistently displaying an interstitial pattern of medullary involvement. A nodular and/or diffuse pattern of medullary infiltration was not seen in any of the cases investigated. The same holds true concerning medullary fibrosis and osteolytic changes. Based on in situ hybridization, all MM cases showed monoclonal lightchain restriction, which was vice versa excluded in all RP cases.

\section{AgNOR Area and Count}

The results of AgNOR area and count are summarized in tables 1 (AgNOR area) and 2 (AgNOR count). Due to the limited number of high-grade MM available in this study ( $\mathrm{n}=3$ ), no attempt was made to statistically compare this group with the other groups. Therefore, in tables 1 and 2 no $p$ values are provided concerning highgrade MM. 
Table 1. AgNOR area in RP and MM in cytologic smears

\begin{tabular}{|c|c|c|c|c|c|c|}
\hline \multirow[t]{2}{*}{ Specimen } & \multicolumn{5}{|c|}{ AgNOR area, $\mu \mathrm{m}^{2}$} & \multirow[t]{2}{*}{$\mathrm{p}$ value } \\
\hline & mean & range & $95 \% \mathrm{CI}$ & SE & SD & \\
\hline $\mathrm{RP}(\mathrm{n}=20)$ & 6.2 & $3.8-8.4$ & $4.7-7.3$ & 1.3 & 5.8 & $<0.001$ \\
\hline Low-grade MM (n = 23) & 23.4 & $19.2-26.7$ & $20.1-25.6$ & 2.1 & 10.1 & \\
\hline $\mathrm{RP}(\mathrm{n}=20)$ & 6.2 & $3.8-8.4$ & $4.7-7.3$ & 1.3 & 5.8 & $<0.001$ \\
\hline Intermediate-grade MM $(\mathrm{n}=22)$ & 36.2 & $28.5-42.3$ & $29.3-38.1$ & 2.6 & 12.2 & \\
\hline Low-grade MM (n = 23) & 23.4 & $19.2-26.7$ & $20.1-25.6$ & 2.1 & 10.1 & 0.02 \\
\hline Intermediate-grade MM $(\mathrm{n}=22)$ & 36.2 & $28.5-42.3$ & $29.3-38.1$ & 2.6 & 12.2 & \\
\hline High-grade MM $(n=3)$ & 90.3 & $66.2-101.5$ & $76.1-98.4$ & 3.8 & 6.6 & \\
\hline
\end{tabular}

$\mathrm{CI}=$ Confidence interval for mean; $\mathrm{SE}=$ standard error; $\mathrm{SD}=$ standard deviation.

Table 2. AgNOR count in RP and MM in cytologic smears

\begin{tabular}{|c|c|c|c|c|c|c|}
\hline \multirow[t]{2}{*}{ Specimen } & \multicolumn{5}{|c|}{ AgNOR count } & \multirow[t]{2}{*}{$\mathrm{p}$ value } \\
\hline & mean & range & $95 \% \mathrm{CI}$ & SE & SD & \\
\hline $\mathrm{RP}(\mathrm{n}=20)$ & 3.68 & $1-6$ & $1.8-5.2$ & 0.2 & 0.9 & \multirow[t]{2}{*}{0.7} \\
\hline Low-grade MM $(\mathrm{n}=23)$ & 5.36 & $1-7$ & $3.2-5.9$ & 0.4 & 1.9 & \\
\hline $\mathrm{RP}(\mathrm{n}=20)$ & 3.68 & $1-6$ & $1.8-5.2$ & 0.2 & 0.9 & \multirow[t]{2}{*}{0.02} \\
\hline Intermediate-grade MM $(\mathrm{n}=22)$ & 6.52 & $2-8$ & $5.4-7.0$ & 0.3 & 1.4 & \\
\hline Low-grade MM (n = 23) & 5.36 & $1-7$ & $3.2-5.9$ & 0.4 & 1.9 & \multirow[t]{2}{*}{0.03} \\
\hline Intermediate-grade MM $(\mathrm{n}=22)$ & 6.52 & $2-8$ & $5.4-7.0$ & 0.3 & 1.4 & \\
\hline High-grade MM $(n=3)$ & 7.21 & $3-9$ & $7.1-7.8$ & 0.7 & 1.2 & \\
\hline
\end{tabular}

$\mathrm{CI}=$ Confidence interval for mean; $\mathrm{SE}=$ standard error; $\mathrm{SD}=$ standard deviation.

The mean AgNOR area was found to be significantly higher in low- and intermediate-grade $\mathrm{MM}$ compared to $R P(p<0.001)$. There was also a significant $(p=0.02)$ difference in terms of the mean AgNOR area between lowand intermediate-grade MM, accompanied by a trend toward a further increase in the mean AgNOR area in highgrade MM (fig. 1, table 1).

Using receiver-operating characteristic curve (ROC) analysis, the optimal cutoff point was found to be 13.8 (95\% confidence interval: 11.2-15.6) for the differentiation between RP and MM.

The mean AgNOR count failed to differ significantly between RP and low-grade MM, although there were significant differences between RP and intermediate-grade MM ( $p=0.02)$, and between low- and intermediate-grade
MM ( $\mathrm{p}=0.03)$, accompanied by a trend toward a further increase in the mean AgNOR count in high-grade MM (table 2).

\section{Reproducibility of the Data}

Reproducibility analysis revealed substantial intraand interobserver concordance concerning AgNOR area and count (table 3).

\section{Discussion}

Evaluation of interphase AgNORs represents an independent prognostic parameter for various types of human malignancies, e.g. pharyngeal carcinoma, 
Table 3. Intra- and interobserver variability in terms of AgNOR area and count determination

\begin{tabular}{lll}
\hline & Agreement & $\kappa$ value \\
\hline $\begin{array}{ll}\text { Intraobserver variability } \\
\quad \text { Count }\end{array}$ & \\
$\quad$ Area & $84 \%$ & 0.76 \\
Interobserver variability & & 0.77 \\
$\quad$ Count & $85 \%$ & \\
$\quad$ Area & $86 \%$ & 0.75 \\
& & 0.78 \\
\hline
\end{tabular}

prostate cancer, renal cell carcinoma and MM [13]. Concerning the latter, AgNOR counts have been reported to correlate with histologic grading [14] and to be reflective of myeloma cell mass and myeloma cell kinetics [9].

We present the first study focusing on the biological principle of comparing AgNOR area and count in bone marrow aspirates in the setting of reactive and neoplastic PC proliferations to elucidate so far neglected conventional morphologic parameters, aiming to expand the multiparametric approach established in this scenario. Since the lack of a standardized silver-staining protocol has led to misinterpretation [6], a standardized silver-staining procedure [12] was employed in this study.

We found a significantly increased mean AgNOR area in MM compared with RP. Among the MM cases investigated, conventional dedifferentiation seemed to follow a trend towards higher mean AgNOR areas, confirming the role that has been attributed to the mean AgNOR area in various other malignancies [15-19]. Our results are also in line with studies on the association between mean AgNOR count and histologic grading in MM $[9,14]$.

The mean AgNOR count has been suggested to be an index for $M$ protein synthesis rather than an independent prognostic factor in MM [20]. Therefore, from a morphological point of view, AgNOR area and count appear to morphologically reflect different aspects behind the neoplastic progression of MM. This might explain the conflicting reports on the questionable prognostic significance of the mean AgNOR count in MM $[8,20]$.

Routinely, sufficient data are commonly obtained by flow cytometry of bone marrow aspirates. However, since the latter represents an 'amorphological' approach, clinical histopathologists might feel more comfortable when evaluating conventional morphological parameters such as AgNORs.

A possible limitation of our study is the limited number of cases evaluated which might explain the lack of the nodular and/or diffuse pattern of marrow infiltration in any of the trephine biopsies investigated. Therefore, although our data strongly hint at a significant discriminating ability of the mean AgNOR area with respect to differentiation between RP and MM in bone marrow aspirates, these novel findings clearly need to be confirmed by larger prospective clinical trials.

\section{References}

1 Devesa SS, Silverman DT, Young JL Jr, Pollack ES, Brown CC, Horm JW, Percy CL, Myers MH, McKay FW, Fraumeni JF: Cancer incidence and mortality trends among whites in the United States, 1974-84. J Natl Cancer Inst 1987;79:701-770.

2 Grogan TM, Van Camp B, Kyle RA, MüllerHermelink HK, Harris NL: Plasma cell neoplasms; in Jaffe ES, Harris NL, Stein H, Vardiman JW (eds): World Health Organization Classification of Tumours. Pathology and Genetics of Tumors of Haematopoietic and Lymphoid Tissues. Lyon, IARC Press, 2001, pp 142-156.
-3 Ng AP, Wei A, Bhurani D, Chapple P, Feleppa F, Juneja S: The sensitivity of CD138 immunostaining of bone marrow trephine specimens for quantifying marrow involvement in MGUS and myeloma, including samples with a low percentage of plasma cells. Haematologica 2006;91:972-975.

4 Weiss LM, Movahed LA, Chen YY, Shin SS Stroup RM, Bui N, Estess P, Bindl JM: Detection of immunoglobulin light-chain mRNA in lymphoid tissues using a practical in situ hybridization method. Am J Pathol 1990; 137:979-988.

5 Fend F, Kremer M: Diagnosis and classification of malignant lymphoma and related entities in the bone marrow trephine biopsy. Pathobiology 2007;74:133-143.

6 Trere D: AgNOR staining and quantification. Micron 2000;31:127-131.
7 Derenzini M, Trere D: Silver-stained Nucleolar Organizer Regions (AgNOR) (in Italian). Pathologica 2001;93:99-105.

$\checkmark 8$ Pich A, Chiusa L, Marmont F, Navone R: Risk groups of myeloma patients by histologic pattern and proliferative activity. Am J Surg Pathol 1997;21:339-347.

9 Pich A, Chiusa L, Boccadoro M, Marmont F. AgNORs and myeloma prognosis. Leuk Lymphoma 1994;12:383-394.

10 Bartl R, Frisch B, Fateh-Moghadam A, Kettner G, Jaeger K, Sommerfeld W: Histologic classification and staining of multiple myeloma. A retrospective and prospective study of 674 cases. Am J Clin Pathol 1987;87: 342-355. 
11 Schaefer HE: Histological processing of iliac crest biopsies based on decalcification and paraffin embedding with reference to osteolytic and hematologic diagnosis (in German). Pathologe 1995;16:11-27.

-12 Fiorella RM, Saran B, Kragel PJ: AgNOR counts as a discriminator of the endocervix. Acta Cytol 1994;38:527-530.

-13 Pich A, Chiusa L, Margaria E: Prognostic relevance of AgNORs in tumor pathology. Micron 2000;31:133-141.

14 Pich A, Chiusa L, Margaria E: Role of the argyrophilic nucleolar organizer regions in tumor detection and prognosis. Cancer Detect Prev 1995;19:282-291.

15 Nakayama K, Abe R: Argyrophilic nucleolar organizer region (AgNOR) area per nucleus as a prognostic factor in breast cancer. J Surg Oncol 1995;60:160-167.
16 Trere D, Ceccarelli C, Migaldi M, Santini D, Taffurelli M, Tosti E, Chieco P, Derenzini M Cell proliferation in breast cancer is a major determinant of clinical outcome in nodepositive but not in node-negative patients. Appl Immunohistochem Mol Morphol 2006;14:314-323.

17 Trere D, Pession A, Basso G, Rondelli R, Masera G, Paolucci G, Derenzini M: Prognostic relevance of pretreatment proliferative rapidity of marrow blast cells in childhood acute lymphoblastic leukaemia. Br J Cancer 1994;70:1198-1202.
8 Tosi P, Cintorino M, Santopietro R, Lio R, Barbini P, Ji H, Chang F, Kataja V, Syrjänen S, Syrjänen K: Prognostic factors in invasive cervical carcinomas associated with human papillomavirus (HPV). Quantitative data and cytokeratin expression. Pathol Res Pract 1992;188:866-873.

19 Thickett KM, Griffin NR, Griffiths AP, Wells M: A study of nucleolar organizer regions in cervical intraepithelial neoplasia and human papillomavirus infection. Int $\mathrm{J}$ Gynecol Pathol 1989;8:331-339.

-20 Papadhimitriou SI, Daskalopoulou D, Tsaftaridis P, Markidou S, Stamatelou M: Evaluation of argyrophilic nucleolar organiser regions (AgNORs) in multiple myeloma. J Clin Pathol 2000;53:462-465. 